\title{
CrystEngComm
}

Check for updates

Cite this: CrystEngComm, 2020, 22, 4887

Received 8th April 2020,

Accepted 19th June 2020

DOI: $10.1039 / \mathrm{d} 0 \mathrm{ce} 00540 \mathrm{a}$

rsc.li/crystengcomm

\section{Flow-driven crystal growth of lithium phosphate in microchannels $\uparrow$}

\author{
Michael Emmanuel, ${ }^{a}$ Dezső Horváth (iD ${ }^{\mathrm{b}}$ and Ágota Tóth (iD *a
}

\section{Introduction}

The development of rechargeable batteries ${ }^{1,2}$ and the high demand for electric cars in recent years have led to increased popularity of the lithium ion. Lithium is not only useful in the battery technology but also has gained widespread industrial interest. It is an effective desiccant ${ }^{3}$ for ceramics and glass due to the high hygroscopy of its bromide and chloride salts. Hollow shaped lithium phosphate catalyzes propylene oxide isomerization, ${ }^{4}$ lithiated esters are high temperature resistant lubricants, ${ }^{5}$ and various lithium salts are used as medicine for the treatment of mental illnesses. ${ }^{6}$

With all the applications of lithium, the common source depends on its mining from minerals, ${ }^{7}$ certain soils, ${ }^{8}$ underground $^{9}$ or geothermal waters. ${ }^{10,11}$ These activities are costly and detrimental to the environment; hence recovery from spent lithium ion batteries is a very important step in using a completely environment-friendly source of energy. ${ }^{8,12}$

Lithium phosphate is the product of lithium ion battery recycling; ${ }^{12,13}$ hence, understanding its precipitation kinetics is of great importance if recycling is to be made efficient. Flow-driven precipitation where reactants are pumped at a specific flow rate into a chamber filled with the other reacting species is a convenient technique to provide information on how nucleation and crystal growth processes

\footnotetext{
${ }^{a}$ Department of Physical Chemistry and Materials Science, University of Szeged, Rerrich Béla tér 1, Szeged, Hungary. E-mail: atoth@chem.u-szeged.hu; Fax: +3662 546482; Tel: +3662544614

${ }^{b}$ Department of Applied and Environmental Chemistry, University of Szeged, Rerrich Béla tér 1, Szeged, H-6720, Hungary

$\dagger$ Electronic supplementary information (ESI) available. See DOI: 10.1039/ d0ce00540a
}

take place. ${ }^{14-17}$ Furthermore, it also enables the control of crystal size and morphology ${ }_{18-20}$ making it feasible to study and analyze crystal formation. For example, the change from the spherulite form of insulin to a packed fiber structure ${ }^{18}$ or the enhancement of the calcite form of calcium carbonate ${ }^{21}$ is a result of confinement and a high flow rate. Ultrasound assistance in mixing during tubular crystallization, besides eliminating pipe clogging, helps to control crystal size as well. ${ }^{22}$ The production of active pharmaceutical ingredients via flow chemistry has led to the syntheses of many promising compounds. ${ }^{23}$ Metal ions in the form of sparingly soluble salts can also be spatially separated from their homogeneous solution mixture by the appropriate choice of precipitation. ${ }^{24}$ Even the type of fluid flow significantly alters the product distribution as polymorphic crystallization of L-histidine can be promoted by periodic Taylor vortex flow. ${ }^{25}$

Microfluidics serves as a special tool to study crystallization. ${ }^{26,27}$ Small to single crystals of proteins have been produced efficiently in droplet based devices ${ }^{28-30}$ where nucleation and growth can be decoupled by varying the flow rate and the reactant concentrations. ${ }^{31,32}$ When reactants are flowed parallel in microchannels, one-dimensional inorganic membranes may develop, ${ }^{33-35}$ offering the ease of monitoring the tubular growth of a confined chemical garden. The coflow design also allows the effective screening of crystal polymorphs, ${ }^{36}$ essential for creating the desired crystalline material. In order to understand pathological microcalcification, microchannels with similar dimensions to the collecting duct in human kidneys have been utilized as biomimetic models for calcium oxalate formation. ${ }^{37}$ The confinement due to the microfluidic conditions slows down the conversion of the unstable amorphous calcium carbonate into the crystalline form as opposed to the well-stirred 
reaction where the stable crystalline form appears within seconds to minutes of mixing. ${ }^{38-40}$

Building upon the versatile applicability of microfluidics, we first study experimentally the precipitation of lithium phosphate in a microchannel and study the effect of flow on the growth of the precipitate particles. The results are then corroborated by simple calculations.

\section{Experimental section}

\subsection{Experimental setup}

A pressure generator (FLPG plus, Fluigent) with manual pressure regulators and pressure sensors produced high quality dry air up to a maximum pressure of 2.3 bar. The pressure generator was coupled to a flow controller (Flow EZTM) in a dual lineup series enabling the control of the pressure to minimize the fluctuation in the flow. A flow sensor (Fluigent) was connected to each of the controller units to allow flow rate programming and increased reproducibility.

Two separate reservoirs (Fluiwell 1C-50) - one for lithium chloride and one for sodium phosphate - were used with PTFE tubes (ID $=0.5 \mathrm{~mm}$ ) linked to the pressure controller as shown in Fig. 1. The tubes passing through the flow sensors were also connected to an $\mathrm{H}$-shaped and irreversibly sealed channel (Microfluidic Chipshop) serving as a microreactor made from poly(methyl methacrylate) with channel dimensions of $w=300 \mu \mathrm{m}$ middle width, $150 \mu \mathrm{m}$ inlet/outlet width, $75 \mu \mathrm{m}$ depth, and $13.5 \mathrm{~mm}$ length. The microreactor was placed on an inverted research microscope (Nikon Eclipse Ts2R) coupled with a high-speed camera (Nikon LVTV) to monitor the progressive growth of the particles in the microreactor and images were saved at time intervals of $30 \mathrm{~s}$ to a computer system.

\subsection{Formation of lithium phosphate}

Equal volumes from analytical grade chemicals of LiCl (VWR) and $\mathrm{Na}_{3} \mathrm{PO}_{4}$ (Sigma-Aldrich), in a stoichiometric ratio of $R=$

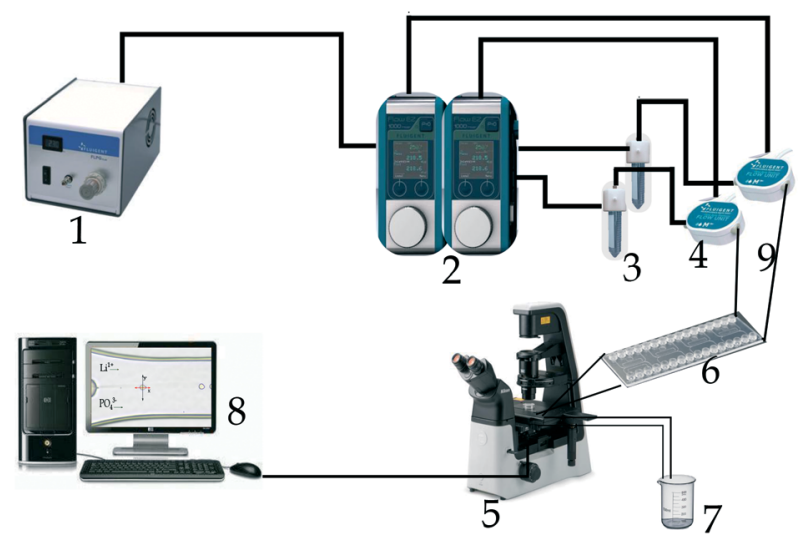

Fig. 1 Fully automated microfluidic setup: 1. pressure generator, 2. pressure controller - dual lineup series, 3. reservoirs, 4. flow sensors, 5. microscope with a camera, 6. microreactor, 7. drain reservoir, 8. computer/readout, and 9. PTFE tube connectors.
$\left[\mathrm{Li}^{+}\right] /\left[\mathrm{PO}_{4}{ }^{3-}\right]=3$ with $\left[\mathrm{Na}_{3} \mathrm{PO}_{4}\right]=0.1 \mathrm{M}$, were prepared in deionized water, filtered through a $25 \mathrm{~mm}$ syringe filter cap (cellulose acetate membrane with $0.2 \mu \mathrm{m}$ pore size, VWR) and poured into the reservoirs. The flow rate was increased

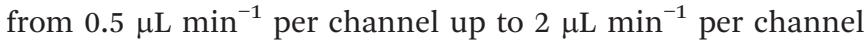
in steps of $0.25 \mu \mathrm{L} \mathrm{m^{-1 }}$ per channel, for each separate experiment yielding the total flow rate $\left(q_{V}\right)$ in the range of 1 $\mu \mathrm{L} \min ^{-1} \leq q_{V} \leq 4 \mu \mathrm{L} \min ^{-1}$. The experiments were run for a maximum of $45 \mathrm{~min}$ to avoid clogging of the reactor. The precipitate product was collected through the two outlets and kept for analyses. After stopping the flow, the entire system underwent a cleaning procedure: first, by pumping filtered deionized water into the channel at higher pressure, the precipitate formed in the microreactor was collected. Then, 1.0 M hydrochloric acid was injected to dissolve any precipitate remaining in the microreactor, followed by purging the channels with deionized water again and blowing with dry air for about 2-4 minutes to dry the channels. The entire procedure was repeated with a concentration ratio of $R$ $=6$ corresponding to a non-stoichiometric composition of reactants with $\mathrm{LiCl}$ in excess.

To characterize the particles, separate reference experiments were also performed in a well-stirred reactor of a $100 \mathrm{~mL}$-volume beaker where equal volumes $(25 \mathrm{~mL})$ of the chemicals were mixed under vigorous stirring for $25 \mathrm{~min}$. The precipitate was filtered and washed several times with deionized water then dried and used for characterization.

\subsection{Characterization}

The density of the reactants was measured with a precision of $10^{-4} \mathrm{~g} \mathrm{~cm}^{-3}$ using a density meter (Anton Paar, DMA 500).

Particle position and size were determined from the stored images by a specially designed macro of ImageJ where the edge of the precipitate was identified as points of inflection in the gray scale intensity collected along and transverse to the flow.

The microstructure of the particles was determined from the images using a scanning electron microscope (Hitachi S4700). The product was dried and then placed on adhesive carbon paper, and sputtered with gold in a vacuum for 1 minute to increase the conductivity of the particle surface. The vacuum accelerating voltage in the scanning electron microscope was $20 \mathrm{kV}$, at a working distance of $12 \mathrm{~mm}$. The X-ray diffractograms of the powdered $\mathrm{Li}_{3} \mathrm{PO}_{4}$ samples were recorded on a Philips X-ray diffractometer with copper $\mathrm{K} \alpha=$ $0.1542 \mathrm{~nm}$ as the radiation source at ambient temperature in the $2-60^{\circ}(2 \theta)$ range applying a $0.02^{\circ}$ step size. The percentage crystallinity was calculated as the ratio of the area of crystalline peaks to the total area of all peaks. The crystallite sizes were determined using the Scherrer equation

$$
D=\frac{k \lambda}{\beta \cos \theta}
$$

where $k=0.9$ is the Scherrer constant, $D$ is the crystallite size, $\lambda$ is the wavelength of the radiation source, $\beta$ is the width at 
half of the maximum intensity and $\theta$ is the Bragg angle in radians.

\section{Results and discussion}

By the use of a fully automated microfluidic setup, lithium chloride and sodium phosphate solutions are pumped simultaneously with the same flow rate into the microreactor. The two reactants come into contact at the middle of the channel where nucleation starts. The precipitation takes place in the middle along the flow giving rise to a so-called contact line. The nucleation itself is stochastic in time, implying that the time of appearance of the first precipitate particle in the channel is not a reproducible entity.

Injecting the reactants at a stoichiometric ratio of $R=3$, we have observed that the first particles appear at 8-10 $\mathrm{min}$ after starting the flow along the contact line. There are many nucleation sites yielding small-sized precipitate particles and hence hindering the growth of the individual particles (see Fig. 2(a)).

Upon increasing $R$ to 6, even after 15-20 min, fewer nuclei appear initially as orthorhombic crystals then grow into spherical aggregates which evolve separately as shown in Fig. 2(b). The well-spaced particles along the contact line are surrounded with more cations in the system than anions because of the lithium ion excess.

To characterize the growth of individual particles, a minimum of three parallel experiments have been performed with a stoichiometric ratio of $R=6$ for every flow rate. For the selected particles, their position is monitored as a function of time. A typical growth profile is illustrated in Fig. 3, where the temporal evolution of the edge of a precipitate particle is presented in the transverse direction with $y=0$ position corresponding to the center vertical plane of the channel and $y>0$ to the side of the lithium source. The distance between the two positions yields the diameter
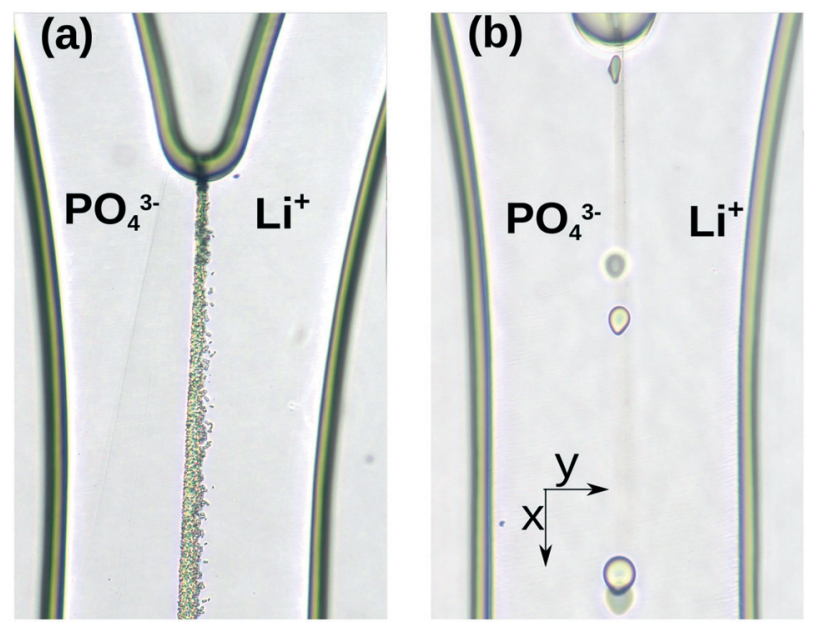

Fig. 2 Precipitate particle growth in the microchannel with $w=300$ $\mu \mathrm{m}, q_{v}=3.0 \mu \mathrm{L} \mathrm{min}^{-1}$ and chemical compositions, (a) $R=3$ and (b) $R=$ 6 , at $t=45 \mathrm{~min}$.

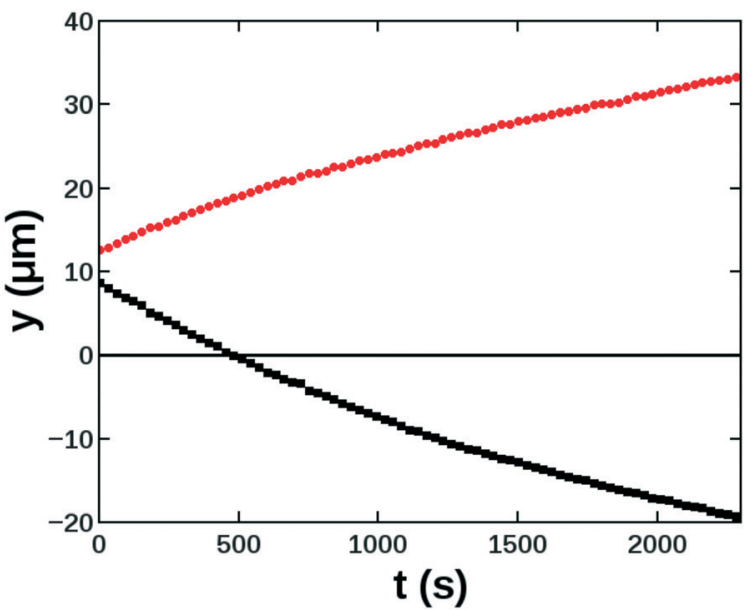

Fig. 3 Typical example of the growth characteristics of the transverse extent of a single particle $462 \mu \mathrm{m}$ from the inlet with $R=6$ and $q_{V}=$ $3.0 \mu \mathrm{L} \mathrm{min}{ }^{-1}$. Position $y=0$ corresponds to the middle of the channel. The edge plotted with red circles faces the side of the lithium inlet.

of the particle transverse to the flow, i.e., along the $y$-axis, which is also measured in order to construct the growth profiles. The crystals form mainly in the vicinity of the contact line but on the side of the lithium chloride inlet which is due to its higher concentration gradient.

A similar technique is applied to determine the particle growth along the flow allowing us to observe the effect of flow in both directions. First at a given flow rate, several particles are chosen and their growth characteristics are determined. One example case is summarized in Fig. 4, where the growth profiles along the two directions are depicted for several particles (see the ESI† for more data). For a given injection rate, the particle diameters along the flow increase linearly with time ( $c f$. Fig. 4(a)) for the individual particles independent of the time of appearance and their position as long as the particles are sufficiently separated from each other. From the slope, therefore, we can obtain a constant growth rate of $2.0 \pm 0.2 \mu \mathrm{m} \mathrm{min} \mathrm{m}^{-1}$ along the flow independent of the particle position and for injection rates in

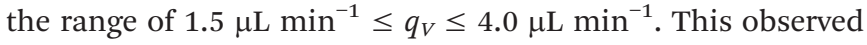
behavior implies that the supersaturation cannot change significantly along the flow ( $x$-axis). This can be rationalized by considering the mean linear flow rate, which falls in the range of 1.1-3.0 $\mathrm{mm} \mathrm{s}^{-1}$ leading to a residence time of less than one second in the view area for the injected fluid. The precipitation reaction is the rate-determining factor yielding a reaction-controlled growth ${ }^{41}$ along the flow as the reactants are continuously brought to the contact line by the flow.

The precipitation process in the transverse direction, however, slows down. The size of the precipitate particles along the $y$-axis scales with time according to the power law $d_{y}=k t^{\alpha}$ as shown in Fig. 4(b), where the exponent is invariant to the injection rate under our experimental conditions. This is the result of the decrease in supersaturation as we move away from the contact line, which lowers the driving force of precipitation. The fast supply of reactants by the flow affects 

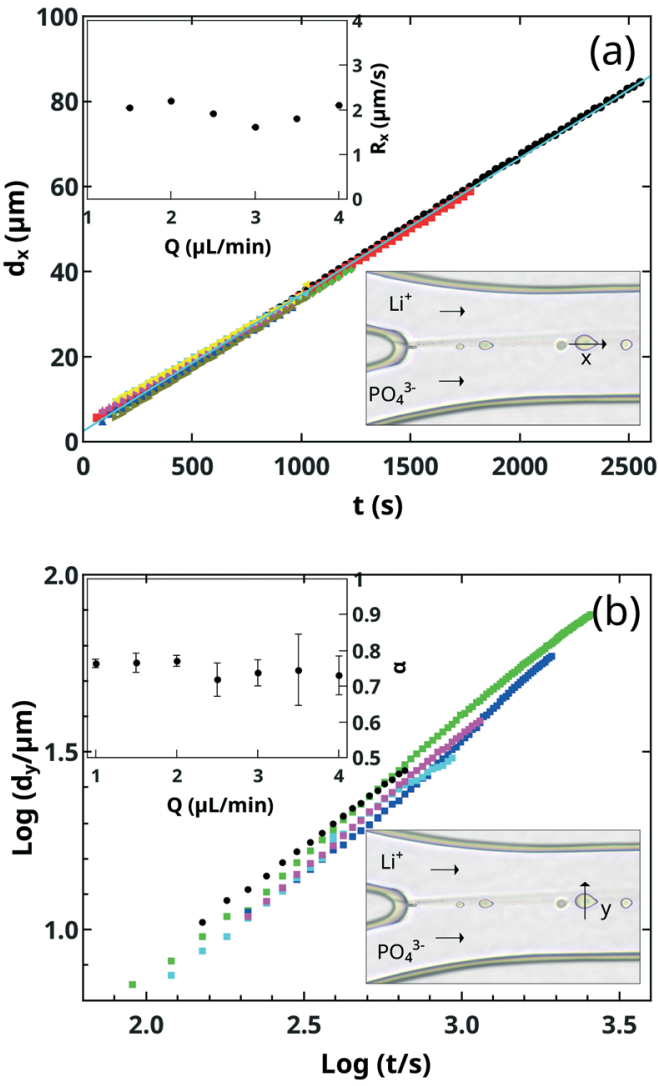

Fig. 4 Precipitate particle growth profiles for $q_{V}=2.5 \mu \mathrm{L} \mathrm{min}{ }^{-1}$ along (a) and transverse to (b) the reactant flow. Particles are 315-1064 $\mu \mathrm{m}$ from the inlet. In (a), the inset shows the independence of the growth rate $\left(R_{x}\right)$ from the injection rate. In (b), the inset shows the scaling exponent $(\alpha)$ of the transverse growth rate.

the entire width of the microchannel; therefore the determined exponent is greater than 0.5 , which is a characteristic of reactions between initially segregated reactants with only a diffusional support. ${ }^{42}$

\subsection{Modeling of the concentration field in the microchannel}

The flow in the reactor is laminar as indicated by the Reynolds number in the range of $0.09-0.36$ as calculated according to

$$
\operatorname{Re}=\frac{u_{x} d_{\mathrm{H}}}{v}=\frac{2 q_{V}}{(w+h) v}
$$

where the hydraulic diameter $\left(d_{\mathrm{H}}\right)$ for the microfluidic reactor is defined as $d_{\mathrm{H}}=2 w h /(w+h)$ and $v$ is the kinematic viscosity of the water as we are dealing with dilute solutions. The Péclet number that is associated with the ratio of the advective transport rate to that of diffusive is defined as

$$
\mathrm{Pe}=\frac{u_{x} L_{x}}{D}
$$

where the characteristic length scale $\left(L_{x}\right)$ is $1 \mathrm{~mm}$. In the direction of flow, $\mathrm{Pe}=450-1800$; therefore the diffusional contribution to transport along the $x$-axis is negligible. In the transverse direction, however, diffusion is the main form of transport with negligible advective contribution; hence Fick's second law can describe the evolution of concentration along the $y$-axis prior to nucleation. The input flow builds up a stationary concentration profile where the coordinate along the flow $(x)$ expresses the mixing or residence time between the two liquids as $t=x / u_{x}$. Since the input solutions are homogeneous, an analytical solution exists for the concentration profiles with diffusion along the $y$-axis and advection along the $x$-axis according to

$$
\begin{gathered}
{\left[\mathrm{Li}^{+}\right]=\frac{\left[\mathrm{Li}^{+}\right]_{0}}{2}\left[1+\operatorname{erf}\left(\frac{y}{2 \sqrt{x D / u_{x}}}\right)\right]} \\
{\left[\mathrm{PO}_{4}{ }^{3-}\right]=\frac{\left[\mathrm{PO}_{4}{ }^{3-}\right]_{0}}{2}\left[1+\operatorname{erf}\left(\frac{-y}{2 \sqrt{x D / u_{x}}}\right)\right]}
\end{gathered}
$$

where $D$ is the diffusion coefficient of ions, approximated to be $2000 \mu^{2} \mathrm{~s}^{-1}$ for dilute aqueous solutions. For the reaction

$$
3 \mathrm{Li}^{+}(\mathrm{aq})+\mathrm{PO}_{4}{ }^{3-}(\mathrm{aq}) \rightleftharpoons \mathrm{Li}_{3} \mathrm{PO}_{4}(\mathrm{~s})
$$

it results in a stationary reaction quotient $Q=\left[\mathrm{Li}^{+}\right]^{3}\left[\mathrm{PO}_{4}{ }^{3-}\right]$, that defines a zone of supersaturation along the contact line, as shown in Fig. 5 for $R=6$. The line of maximum
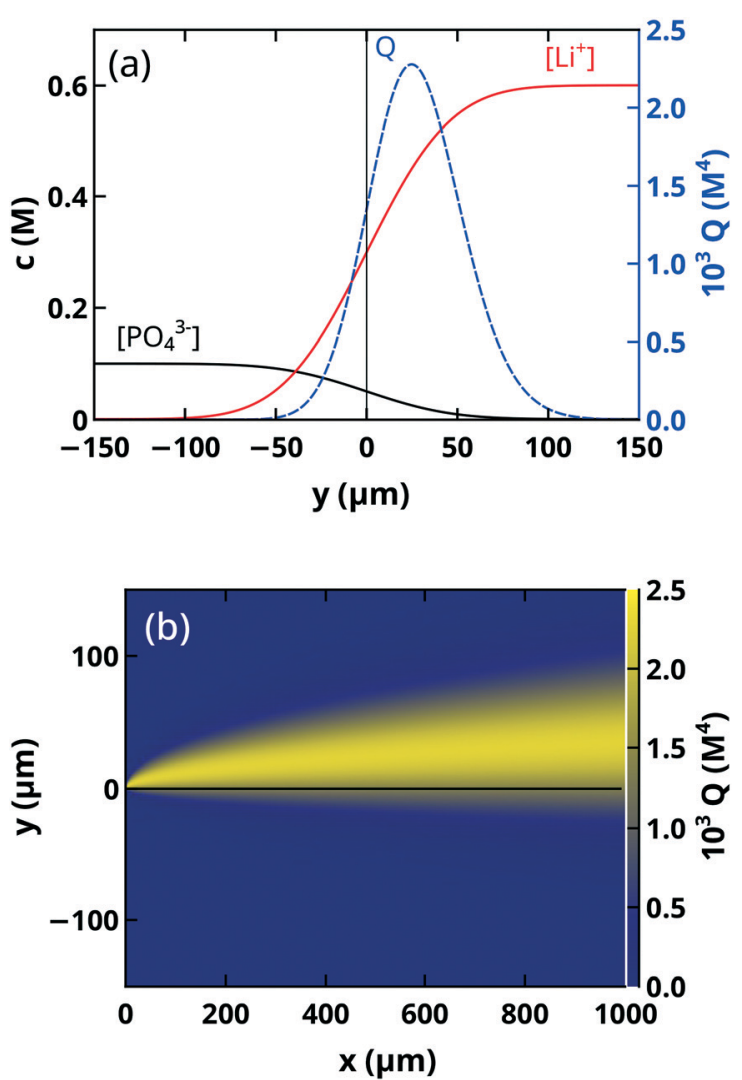

Fig. 5 Stationary concentration profiles of reactants (solid lines) and the reaction quotient (dashed line) at position $x=500 \mu \mathrm{m}$ with $R=6$ and $\left[\mathrm{PO}_{4}{ }^{3-}\right]=0.1 \mathrm{M}(\mathrm{a})$. Spatial distribution of the reactant quotient $(Q)$ characterizing the supersaturation in the view area (b). 
supersaturation is located on the side of lithium input because of the greater exponent of lithium in the reaction quotient. The increase in the maximum value is on the order of a few percent within the observation window; therefore nucleation along this line can occur anywhere with approximately the same probability.

By considering the spatial distribution of the supersaturation, we can rationalize the growth rate of precipitate particles. In the vicinity of the contact line, the vertical $x z$-plane is characterized by an almost constant supersaturation; hence the growth rate of isolated particles $\left(R_{x}\right)$ along the flow remains constant. Transverse growth on the other hand encounters a significant lowering of supersaturation; therefore the growth rate decreases with time. The scaling exponent is greater than 0.5 , which indicates that the fresh reactants are transported by advective transport besides diffusion to the surface of the precipitate particles.

For more accurate simulation to describe the spatial distribution of the precipitate particles at the time of nucleation, the density difference between the injected liquids has to be considered as well. Although under the experimental conditions the densities of the reactant solutions, $1.0153 \mathrm{~g} \mathrm{~cm}^{-3}$ for $0.1 \mathrm{M} \mathrm{Na}_{3} \mathrm{PO}_{4}$ and $1.0111 \mathrm{~g} \mathrm{~cm}^{-3}$ for $0.6 \mathrm{M} \mathrm{LiCl}$, are comparable, weak buoyant forces can arise in the $y z$-plane transverse to the main flow. This additional fluid motion will further increase the asymmetry in the spatial distribution of precipitate particles sedimented in the microfluidic reactor.

\subsection{Microstructure}

The morphology visualized by the SEM images of the particles from the well-stirred system and the microchannels appears similar (see Fig. 6); spherical particles with a spherulite-like structure are formed which consist of small rod-like crystallites of about 1-2 $\mu \mathrm{m}$ in size (see the ESI $\dagger$ for

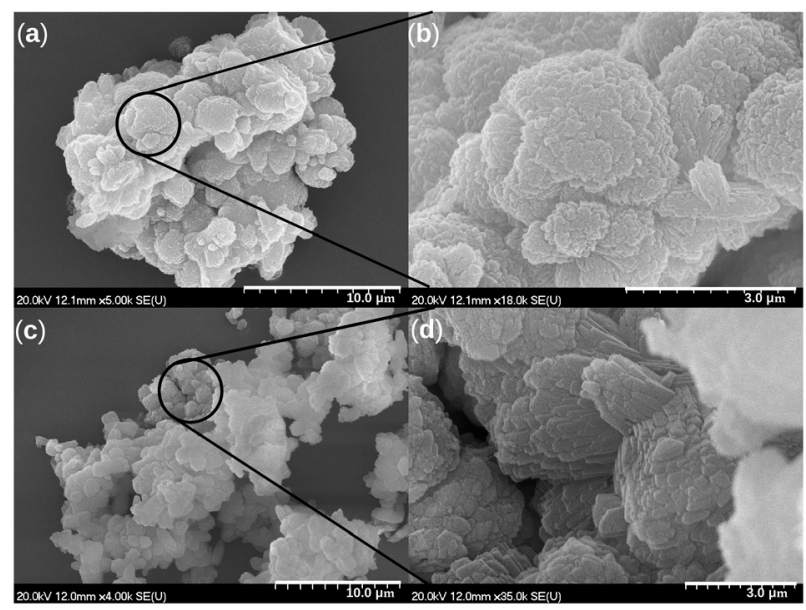

Fig. 6 SEM images of precipitate particles (a) from a well-stirred system with (b) an enlargement and (c) from the microchannel with (d) an enlargement for $R=6$.
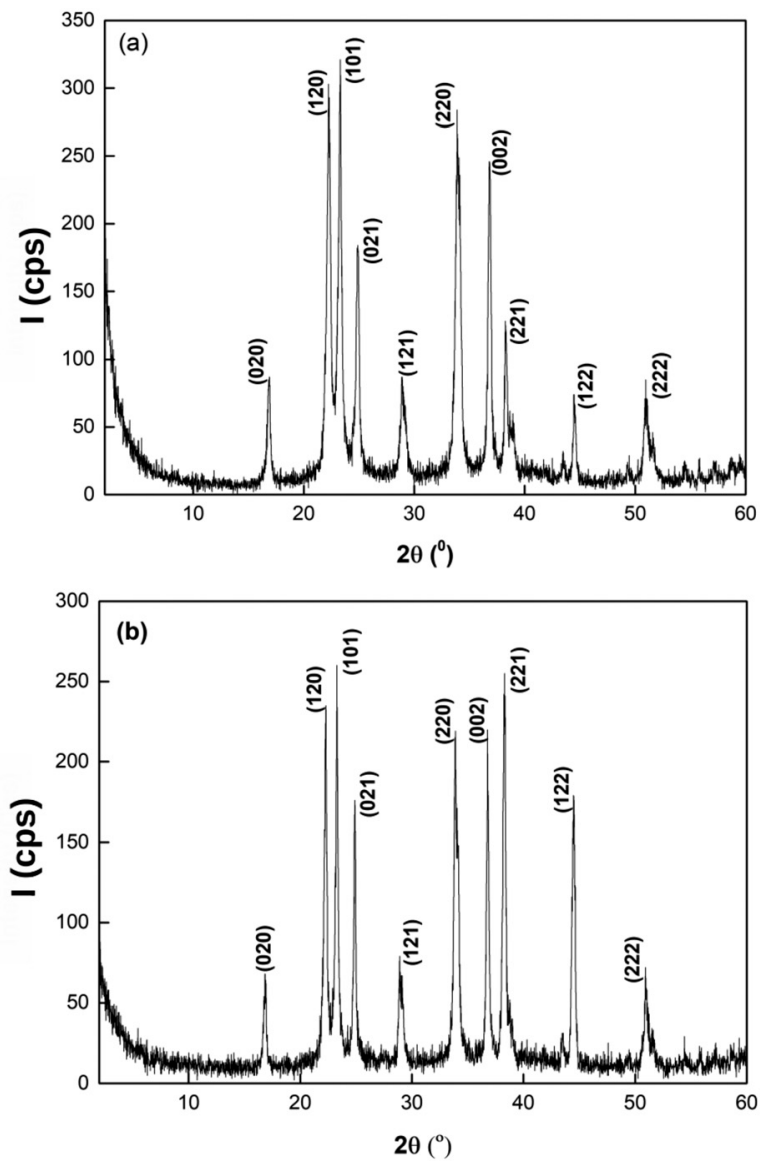

Fig. 7 X-ray diffractograms of samples (a) from the well-stirred experiment and (b) from the microchannel.

further images.) Besides the crystallites, amorphous particles are also observable.

From the diffractograms in Fig. 7, we have identified that the crystals are the orthorhombic, low form of lithium phosphate. ${ }^{43}$ The X-ray diffraction data also indicate that the lithium phosphates obtained from both the microchannel and the well-stirred reference system belong to the same space group of $\mathrm{Pmn}_{1}$ (orthorhombic) ${ }^{43}$ which corresponds to $\beta-\mathrm{Li}_{3} \mathrm{PO}_{4}$ prepared mostly from a wet chemical reaction, ${ }^{44}$ with corner-sharing tetrahedra pointing towards the same direction along the main $c$ axis. ${ }^{45,46}$

The crystallinity of the samples is $\sim 67 \%$ from both the reference and the microfluidic system within the experimental error. The average size of the crystallites comprising the polycrystalline aggregates calculated from the Scherrer equation is $18.25 \mathrm{~nm}$ and $23.33 \mathrm{~nm}$ in the wellstirred and in the microfluidic system, respectively, indicating that microfluidics offers a simple possibility to increase the crystallite size in a controlled manner.

\section{Conclusion}

By injecting $\mathrm{LiCl}$ and $\mathrm{Na}_{3} \mathrm{PO}_{4}$ solutions with equal flow rates into a microchannel, we have studied the crystal growth of 
lithium phosphate in the presence of concentration gradients. Nucleation occurs along the thin zone with maximum supersaturation near the contact line, formed in the middle of the microfluidic channel. For individual particles, the growth rate parallel to the flow is constant and independent of the fluid velocity, which is a result of the time independent concentration profiles maintained by the fast injection. It leads to a nearly constant supersaturation along the main flow. In the transverse direction on the other hand, the growth of particles slows down because of the sudden drop in the supersaturation between the initially segregated reactants. As the scaling exponent indicates, advection drives the precipitation process besides diffusion. Particle morphology analysis confirms the production of orthorhombic lithium phosphate with a size controlled by the flow.

\section{Conflicts of interest}

There are no conflicts to declare.

\section{Acknowledgements}

We acknowledge the help of Dr. Gábor Schuszter with SEM and Ágota Imre-Deák with XRD measurements. This work has also been supported by the National Research, Development and Innovation Office (NN 125746), M-ERA.Net MaSNEC and GINOP-2.3.2-15-2016-00013 projects and the University of Szeged Open Access Fund (4816).

\section{References}

1 J. Goodenough and Y. Kim, Chem. Mater., 2010, 22, 587-603.

2 M. S. Whittingham, Chem. Rev., 2004, 104, 4271-4302.

3 Z. Wang, D. Orejon, K. Sefiane and Y. Takata, Phys. Chem. Chem. Phys., 2019, 21, 1046-1058.

4 H. Li, W. Jiang, W. Ma, H. Qu and Q. Zhong, Chem. Eng. Commun., 2016, 203, 339-344.

5 P. K. Alaboina, J.-S. Cho, M.-J. Uddin and S.-J. Cho, Electrochim. Acta, 2017, 258, 623-630.

6 R. Oruch, M. A. Elderbi, H. A. Khattab, I. F. Pryme and A. Lund, Eur. J. Pharmacol., 2014, 740, 464-473.

7 H. Aral and A. Vecchio-Sadus, Ecotoxicol. Environ. Saf., 2008, 70, 349-356.

8 L. Kavanagh, J. Keohane, G. Garcia-Cabellos, A. Lloyd and J. Cleary, Resources, 2018, 7, 57.

9 B. Shahzad, M. Tanveer, W. Hassan, A. N. Shah, S. A. Anjum, S. A. Cheema and I. Ali, Plant Physiol. Biochem., 2016, 107, 104-115.

10 J. A. Epstein, E. M. Feist and J. Zmora, Hydrometallurgy, 1981, 6, 269-275.

11 C. Fouillac and G. Michard, Geothermics, 1981, 10, 55-70.

12 H. Li, S. Xing, Y. Liu, F. Li, H. Guo and G. Kuang, ACS Sustainable Chem. Eng., 2017, 5, 8017-8024.

13 T. Ryu, J. Shin, J. Ryu, I. Park, H. Hong, B.-G. Kim and K.-S. Chung, Mater. Trans., 2013, 54, 1029-1030.

14 J. H. E. Cartwright, J. M. García-Ruiz, M. L. Novella and F. Otálora, J. Colloid Interface Sci., 2002, 256, 351-359.
15 A. Yashina, F. Meldrum and A. deMello, Biomicrofluidics, 2012, 6, 022001.

16 P. Pusztai, E. Tóth-Szeles, D. Horváth, A. Tóth, A. Kukovecz and Z. Kónya, CrystEngComm, 2015, 17, 8477-8485.

17 R.-B. Zhou, H.-L. Cao, C.-Y. Zhang and D.-C. Yin, CrystEngComm, 2017, 19, 1143-1155.

18 V. Foderá, S. Pagliara, O. Otto, U. F. Keyser and A. M. Donald, J. Phys. Chem. Lett., 2012, 3, 2803-2807.

19 B. Bohner, G. Schuszter, O. Berkesi, D. Horváth and Á. Tóth, Chem. Commun., 2014, 50, 4289-4291.

20 E. Tóth-Szeles, G. Schuszter, A. Tóth, Z. Kónya and D. Horváth, CrystEngComm, 2016, 18, 2057-2064.

21 B. Bohner, G. Schuszter, D. Horváth and Á. Tóth, Chem. Phys. Lett., 2015, 631-632, 114-117.

22 N. Ezeanowi, H. Pajari, A. Laitinen and T. Koiranen, Cryst. Growth Des., 2020, 20, 1458-1466.

23 R. Porta, M. Benaglia and A. Puglisi, Org. Process Res. Dev., 2016, 20, 2-25.

24 E. Tóth-Szeles, B. Bohner, A. Tóth and D. Horváth, Cryst. Growth Des., 2017, 17, 5000-5005.

25 S. Park and W.-S. Kim, Cryst. Growth Des., 2018, 18, 710-722.

26 J. Leng and J.-B. Salmon, Lab Chip, 2009, 9, 24-34.

27 M. Maeki, S. Yamazaki, A. S. Pawate, A. Ishida, H. Tani, K. Yamashita, M. Sugishima, K. Watanabe, M. Tokeshi, P. A. Kenis and M. Miyazaki, CrystEngComm, 2016, 18, 7722-7727.

28 M. Ildefonso, E. Revalor, P. Punniam, J. B. Salmon, N. Candoni and S. Veesler, J. Cryst. Growth, 2012, 342, 9-12.

29 P. Laval, A. Crombez and J.-B. Salmon, Langmuir, 2009, 25, 1836-1841.

30 M. Ildefonso, N. Candoni and S. Veesler, Cryst. Growth Des., 2013, 13, 2107-2110.

31 J.-u. Shim, G. Cristobal, D. R. Link, T. Thorsen, Y. Jia, K. Piattelli and S. Fraden, J. Am. Chem. Soc., 2007, 129, 8825-8835.

32 J. Cavanaugh, M. Whittaker and D. Joester, Chem. Sci., 2019, 10, 5039-5043.

33 B. C. Batista and O. Steinbock, J. Phys. Chem. C, 2015, 119, 27045-27052.

34 Q. Wang, M. R. Bentley and O. Steinbock, J. Phys. Chem. C, 2017, 121, 14120-14127.

35 Q. Wang and O. Steinbock, ChemCatChem, 2020, 12, 63-74.

36 P. Coliaie, M. S. Kelkar, N. K. Nere and M. R. Singh, Lab Chip, 2019, 19, 2373-2382.

37 G. Laffite, C. Leroy, C. Bonhomme, L. Bonhomme-Coury, E. Letavernier, M. Daudon, V. Frochot, J. P. Haymann, S. Rouziére, I. T. Lucas, D. Bazin, F. Babonneau and A. AbouHassan, Lab Chip, 2016, 16, 1157-1160.

38 Y. Zeng, J. Cao, Z. Wang, J. Guo and J. Lu, Cryst. Growth Des., 2018, 18, 1710-1721.

39 Y. Zeng, J. Cao, Z. Wang, J. Guo, Q. Zhou and J. Lu, Cryst. Growth Des., 2018, 18, 6538-6546.

40 A. Perazzo, L. Sicignano, G. Tomaiuolo, R. Marotta, R. Andreozzi and S. Guido, Chem. Eng. Sci., 2019, 207, 581-587. 
41 R. D. Sosa, X. Geng, M. A. Reynolds, J. D. Rimer and J. C. Conrad, Lab Chip, 2019, 19, 1534-1544.

42 L. Gálfi and Z. Rácz, Phys. Rev. A: At., Mol., Opt. Phys., 1988, 38, 3151-3154.

43 E. S. Howard, C. M. Marlene, E. H. Evans and L. Ulmer, Standard X-ray Diffraction Powder Patterns, National Bureau of Standards, U.S. Department of Commerce, 25th edn, 1965.
44 N. I. P. Ayu, E. Kartini, L. D. Prayogi, M. Faisal and A. Supardi, Ionics, 2016, 22, 1051-1057.

45 N. Yabuuchi, Y. Yamakawa, K. Yoshii and S. Komaba, Dalton Trans., 2011, 40, 1846-1848.

46 M. E. Arroyo-deDompablo, R. Dominko, J. M. GallardoAmores, L. Dupont, G. Mali, H. Ehrenberg, J. Jamnik and E. Morán, Chem. Mater., 2008, 20, 5574-5584. 